\title{
Research Paper: Happiness of Male Adolescents With Disabled Physical Mobility: Benefits of Mental Rehabilitation Based on Positive Thinking Skills Training
}

Mohammad Rostami ${ }^{1}$, Erfan Soleimani Sefat ${ }^{1}$, Shayesteh Nejati ${ }^{2}$, Zeinab Mohammad Alipur ${ }^{3}$, Maedeh Naghiyaee ${ }^{1}$, Amirhosain Hosainpour ${ }^{1}$, Jalal Younesi ${ }^{1 *}$

1. Department of Counseling, University of Social Welfare and Rehabilitation Sciences, Tehran, Iran.

2. Birjand Campus of Imam Sajjad, Farhangian University, Birjand, Iran.

3. Department of Consuling, Faculty of Psychology and Education, Kharazmi University, Tehran, Iran.

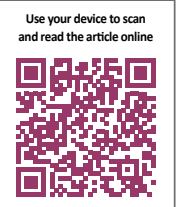

Citation: Rostami M, Soleimani Sefat E, Nejati Sh, Mohammad Alipur Z, Naghiyaee M, Hosainpour A, et al. Happiness of Male Adolescents With Disabled Physical Mobility: Benefits of Mental Rehabilitation Based on Positive Thinking Skills Training. Iranian Rehabilitation Journal. 2017; 15(3):221-226. https://doi.org/10.29252/nrip.irj.15.3.221

https://doi.org/10.29252/nrip.irj.15.3.221

Article info:

Received: 06 Apr. 2017

Accepted: 30 Jul. 2017

Keywords:

Mental health rehabilitation, Physical disabled, Positive thinking, Happiness

\section{A B STRACT}

Objectives: The main purpose of this research was to study the effectiveness of positive thinking skills training on increasing happiness of male adolescents with physical-mobility disability.

Methods: In this study an experimental research design with pre-test, post-test, and control group is used. All adolescents (boys) having disabled physical mobility from all the high schools in southern parts of Tehran in the year 2012-2103 were our statistical community. Among them, 16 students were selected by two-stage sampling, including purposive sampling and random sampling. The samples were randomly divided into two groups: experimental and control groups. Positive thinking skills were performed in 8 sessions of 45 minutes each (twice a week) for the experimental group. In this study, happiness questionnaire was used for collecting data. Analysis of covariance (ANCOVA) and Statistical Package for Social Science 16 (SPSS 16) programs were used for statistical analysis.

Results: Results of the analysis indicated that positive thinking skills training had a significant and positive effect on increasing happiness of adolescents with impaired physical mobility in the experimental group $(\mathrm{P}<0.01)$.

Discussion: Positive thinking skills training can increase the happiness scores of adolescents with disabled physical mobility. Thus, we can say that method used in this study can be appropriate for psycho-educational interventions and counseling of physical mobility disabled male students. 


\section{Introduction}

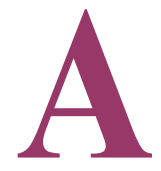

ccording to World Health Organization (WHO) handicap is caused by disruption in the intrapersonal and environmental relationship and can be explained by biological, psychological and social patterns. So, apart from the limitations or problems that make for a disabled person in action, handicap probably may have negative effects on social interactions of persons with disabled physical mobility [1]. People with mobility disabilities particularly experience limitations in motor control, strength, and range of motion. These deficits can reduce participation in community and leisure activities and even negatively affect one's occupational perspectives [2].

According to the statistics of WHO, approximately 650 million people, i.e. about $10 \%$ of the world population suffer from physical disabilities with more than twothirds of them living in developing countries. Also, experts believe that the number of disabled people in all age groups in Iran is about 12 million and 800 people. [3]. The skills to cope with the stresses of life have always been part of the reality of human life. Among the disabled classes, people with physical mobility disability can be doubly affected. Results of researches indicate that people with handicap and physical disability experience a lot of emotional difficulties; effects of which may appear in the form of psychological and behavioral problems such as aggression, anxiety, depression, and lack of joy [4].

Evidence indicates that bodily impairment negatively affects participants' psychological experiences, feelings, and attitude towards their bodies [5,6]. Adolescents with physical disabilities may experience shame, self-hatred, and a negative body image. Emotional tension is hard to reduce or resolve at this age, provoking the individual to feel depressed, inferior and socially rejected [6].

Often, adolescence is considered as a difficult period of life. It is also assumed that teenagers have to deal with big changes in their life and hence they are more anxious. In addition to these problems, impairment (disability) in this sensitive period makes life more difficult [7]. Disabled adolescents are less satisfied with their lives and school activities (satisfaction), have less positive feelings about life, are socially less active (Well-being), and show less feelings of being included (Social belonging) in comparison to their healthy peers [8]. Some studies showed that people with physical mobility disability reported worse Quality of life than the reference group and a higher percentage were at a risk of anxiety and depressive disorder [9].
Happiness has become one of the most important issues in psychology in the last decade. There is only scant available data in the rehabilitation and disability studies on the structure of psychosocial adaptation, affectivity and W-B (well-being), among people with physical disability [10]. There are several definitions of happiness; Seligman believes happiness includes identifying and fostering the most basic potential capabilities and actualizing them in love, parenting, and daily activities. This potential capability can be used as a shield against psychological problems and also be the basis for improving mental health in people [11]. Stewart and colleagues believed that happiness mainly consists of three main components: 1. Having a positive effect 2 . Lack of negative emotions such as depression and anxiety 3 . General satisfaction or during a particular period of life [12].

Teaching positive thinking skills includes a set of strategies to encourage students to identify their positive and good experiences and understand the role of these experiences in increasing their self-esteem and happiness. As a result of training these skills, they in addition to knowing their own positive attributes, will be able to identify the experiences and attributes of others. Eventually, the result of this process will lead to acceptance of an active stance in relation to the surrounding world and increase in the level of happiness of the individual.

In this regard, the results of the research show that positive interventions firstly reduce depression and, secondly they increase the quality of life of the individual. Therefore it was observed that the rate of depression in students who received positive thinking interventions reduced by $50 \%$ on receiving these positive interventions [11]. It is also believed that by teaching positive thinking skills to children who are genetically exposed to depression can keep them away from the risk of depression in the future [11].

Seligman, Rashid, and Parks [13] in a research on depressed people found that those who receive positive interventions while identifying their own positive points could also learn ways to use these identified abilities. As a result, they will be able to greatly overcome their depression. Another study shows that positive psychotherapy can increase the positive descriptions of individuals about themselves and increase their self-esteem and reduce family conflicts [14].

Given the limiting nature of disability and low mental health in students with disabled physical mobility, providing them positive intervention that gives them happiness is vital for these students. On the other hand, this 
research could be a step towards better understanding of people with physical-motor disabilities and survey strategies are supportive of persons with disabilities. The main purpose of this study was to investigate the effect of mental rehabilitation based on positive thinking skills training on increasing happiness in male adolescents with physical mobility disability.

\section{Methods}

\section{Procedure}

In this study experimental research design with pretest, post-test, and control group was used. To this end, among the second and third guidance school students and first and second high school students of educational complex of Imam Ali in the academic years 19911992, 16 subjects were selected based on purposive sampling (students whose happiness scores were lower than average (Average $=41)$ [15] and then randomly assigned to two groups: experimental and control. Both the groups (experimental and control) comprised of 8 students each. It should be noted that the sample selection is determined based on the weekly group of about 8 people including a leader. This provides a good opportunity for interaction within members of the group, providing minimum time for personal activities; this gives a feeling of being in a group [16].

\section{Instrument}

The Oxford Happiness Questionnaire was developed by Miles Argyle in the year 1989. He made the questionnaire based on Beck Depression Inventory (BDI). The Happiness Questionnaire has 29 items; each of the items has to be scored on a scale of 0 to 3 . Respondents choose one of the given options or the closest option according to his or her current state. The minimum and maximum scores that could be obtained are equal to 0 and 87 respectively. The reliability of Questionnaire In research Argyle et al. using Cronbach's alpha was calculated to be $90 \%$. Also, the re-test reliability was calculated to be $78 \%$ for 7 weeks [17].

In Iran, Cronbach's alpha was 0.93. Other psychometric properties are as follows: internal consistency for men equals to 0.94 , and women equals to 0.90 . Retest reliability after 7 weeks equals to 0.78 and Test-retest reliability with an interval of three weeks in a 25 subject sample equals to 0.79 [18]. Also In another study, the Cronbach's alpha was reported to be 0.93 . Also Divergent Validity of this questionnaire using Beck depression inventory was calculated to be -0.65 [19].

\section{Intervention}

After coordinating with the center of Special Education and director of educational complex Tehran Imam Ali, Happiness questionnaires were distributed among 40 high school and guidance school students of the educational complex and 16 students whose happiness score was lower than the average of 41 were entered into the study and randomly assigned to two groups: experimental and control. Positive thinking skills intervention were performed in 8 sessions of 45 minutes each (twice a week) for the experimental group. It should be noted that the post-test was carried out after 48 hours in the experimental group.

\section{Positive psychological package}

\section{Session one}

First session of the Package: Familiarization session is the first session. Here rules and purpose of group formation including administering conditions, the time of each session, and duration of the training is mentioned. In this session, the participants are divided into two groups of four people each.

\section{Session two}

Identify and note positive points. Obviously, this should be done in a relaxed state of mind and with full concentration.

\section{Session three}

Thinking and writing at least five experiences or good memories.

\section{Session four}

Determine the importance and priority of relative strengths raised in the first and second stages. Identify 5 to 8 capabilities and provide evidence of their importance.

\section{Session five}

Sharing all the positive memories and experiences with group members and also noting them down. Listing the points identified in the experiences expressed by members of each group.

\section{Sessions six and seven}

Continue retelling positive memories and identifying positive points in the memories. 
Table 1. Mean scores and standard deviation of happiness in experimental and control groups

\begin{tabular}{ccccccccc}
\hline & \multicolumn{2}{c}{ Pre-Test } & \multicolumn{2}{c}{ Post-Test } & \multicolumn{2}{c}{ Total Pre-Test } & \multicolumn{2}{c}{ Total Post-Test } \\
\cline { 2 - 10 } Gariable & $\mathbf{M}$ & SD & M & SD & M & SD & M & SD \\
Experimental & 25.625 & 6.479 & 59 & 6.782 & 27.625 & 7 & 42.625 & 18.110 \\
Control & 29.625 & 7.347 & 26.250 & 6.627 & & & & \\
\hline
\end{tabular}

\section{Session eight}

Receive positive points of the member narrating his or her experiences and memories from other members of the group. Then comparing the points identified in the final stages with the points expressed in the initial stages and extracting the common points identified in both the stages. This exercise helps members achieve a new understanding of themselves and gives a reliance to identify more points in the future [14].

The objective of the study was explained to students, and the pre-test was distributed among them so that they could fill in the questionnaire carefully and completely. The subjects were assured that they could quit the study whenever they wanted to. They were also assured of the confidentiality of names, identities, and findings. Descriptive (e.g. calculation of mean and standard deviation) and inferential statistical methods (e.g. analysis of covariance (ANCOVA)) were performed to analyze the research assumptions. Statistical package for social science 16.0 (SPSS 16) program was used for statistical analysis.

\section{Results}

Table 1 contains the mean scores and standard deviation of social anxiety components in members of control group and experimental group (comparing pre-test and post-test). According to Table 2, positive thinking skills program affects experimental group $(\mathrm{f}=20.767, \mathrm{P}<0.01)$.

\section{Discussion}

One of the ways to increase the happiness of people in life is to use positive capacities in new ways [11]. This research aims to study the effectiveness of positive thinking skills on rising happiness in male adolescents with impaired physical mobility. After administering intervention programs for physically disabled students for 8 sessions and analyzing the obtained information, results indicate a significant difference between the experimental group and the control group. In other words, because the experimental group received positive thinking skills and the control group received normal school educations it can be concluded that trained package led to an increase in happiness of physical-motor disabled students in the experimental group.

The result so obtained can be explained as first, students who had no prior knowledge of their positive experiences learned in the course of training to take these experiences into consideration. Secondly, as a result of the training, in addition to identifying positive experiences, they also learned about their own positive features (points). Thirdly, students understood the role of positive features (points) in self-respect and self-esteem. Ultimately, students learn that as they have positive features, others also have positive features that deserve attention and respect [11].

It can also be added that because of low happiness and weak self-esteem, adolescents with physical-mobility disability have problems in communicating with others.

Table 2 . Measures of analysis of covariance (ANCOVA)

\begin{tabular}{|cccccc}
\hline Source of Variance & Square & df & Mean of Square & F & Significance Level \\
\hline Covariate (Pre-Test) & 204.639 & 1 & 204.639 & 7.134 & 0.020 \\
\hline Group (Post-Test) & 595.688 & 1 & 595.688 & 20.767 & 0.001 \\
\hline Error & 344.217 & 12 & 28.685 & & \\
\hline Total & 33990.000 & 16 & & & \\
\hline
\end{tabular}


Therefore they have little opportunity to identify their positive features and capacities. But in the safe atmosphere of the group, which is full of respect students will have the opportunity to express their positive experiences and memories and also receive constructive and positive feedbacks from other members. This process for adolescents with disabled physical mobility brings both, more knowledge of abilities and an opportunity for better communication. Therefore, positive thinking skills through these processes have been able to increase the happiness of adolescents with physical mobility disability.

Although there was no similar research in this regard, the results of a number of researches are consistent with the results of this study; including that of Khodayarifard Research [14], findings of Seligman, Rashid and parks [13], and kobau and colleague [11]. Also the results on happiness were in agreement with those of Asgharipoor et al. [20] and Senf and Liau [21]. Also Ruini et al [22], and Wing, Schutte and Byrne [23] obtained the same results in their study about the effectiveness of positive psychotherapy intervention on life satisfaction and mental well-being $[20,21,23]$.

Considering the effectiveness of positive thinking skills in this research, it is recommended that this method be used for the education, counseling, and psychotherapy in adolescent students with physical-mobility disability. Also it is recommended that in future researchers study the effectiveness of teaching positive thinking skills in other mental health variables such as depression, academic achievement, and life expectancy.

\section{Conclusion}

Positive thinking skills training increases the happiness scores of male adolescents with disabled physical mobility. This method has increased the happiness of adolescents by targeting their positive experiences and attributes. Positive thinking skills training can be used as an appropriate method in schools for students with physical mobility disabilities.

The research was conducted only on male subjects. Due to lack of access to more people with physical movement disabilities because of their absence in the training centers and institutions, and sickness the study was conducted on a small study group. Based on the results of this study, it is suggested that researchers interested in positive psychology, especially disability study should investigate the effectiveness of positive thinking in other fields, such as: prevention and treatment of depression, anxiety, adjustment, educational improvement, promot- ing mental health, and coping with disabled people in society in future. According to the findings of this study, it is suggested that positive thinking skills and optimism training be provided in a regular and systematic program in the educational period to both normal and disabled students together. It is also suggested that educational institutions hold workshops and training courses for teachers, counselors, and parents in order to identify and cultivate positive virtues and points, and strengthen and promote feelings of happiness and self-esteem in adolescents.

\section{Acknowledgments}

This article was extracted from research project (Registration code: 432) in Deputy of Research and Technology Student Research Committee, University of Social Rehabilitation And Welfare Sciences. We would like to thank Deputy of Research of University of Social Welfare and Rehabilitation Sciences, Tehran, Iran. We would also like to appreciate the children with physical-motor disability for their cooperation, patience, and endurance until the end of the research.

\section{Conflict of Interest}

The authors declared no conflicts of interest.

\section{References}

[1] Lucas-Carrasco R, Eser E, Hao Y, McPherson KM, Green A, Kullmann L, et al. The Quality of Care and Support (QOCS) for people with disability scale: Development and psychometric properties. Research in Developmental Disabilities. 2011; 32(3):1212-25. doi: 10.1016/j.ridd.2010.12.030

[2] Chang YJ, Chen SF, Huang JD. A Kinect-based system for physical rehabilitation: A pilot study for young adults with motor disabilities. Research in Developmental Disabilities. 2011; 32(6):2566-70. doi: 10.1016/j.ridd.2011.07.002

[3] Jones M, Marks LAB. Law and people with disabilities. In: Smelser NJ, Baltes PB, editors. International encyclopedia of the social \& behavioral sciences. Berlin: Elsevier; 2005.

[4] Baghaei Moghaddam G, Malekpour M, Amiri S, Mowlavi $H$. [The effectiveness of life skills training on anxiety, happiness and anger control of adolescence with physical-motor disability (Persian)]. Journal of Behavioral Sciences. 2012; 5(4):305-10.

[5] Younesi J. Study of development of body image of physically disabled children and adolescents in relation with psychosocial adjustment [PhD thesis]. London: University of London; 1998. 
[6] Taleporos G, McCabe MP. Body image and physical disability--personal perspectives. Social Science \& Medicine. 2002 54(6):971-80. doi: 10.1016/s0277-9536(01)00069-7

[7] Sahli S, Arslan U, Belgin E. Depressive emotioning in adolescents with cochlear implant and normal hearing. International Journal of Pediatric Otorhinolaryngology. 2009; 73(12):1774-9. doi: 10.1016/j.ijporl.2009.09.027

[8] Hallahan DP, Kauffman JM, Pullen PC. Exceptional learners: An introduction to special education. London: Pearson 2011.

[9] Verhoof E, Maurice-Stam H, Heymans H, Grootenhuis M. Health-related quality of life, anxiety and depression in young adults with disability benefits due to childhood-onset somatic conditions. Child and Adolescent Psychiatry and Mental Health. 2013; 7(1):12. doi: 10.1186/1753-2000-7-12

[10] Livneh H, Martz E, Bodner T. Psychosocial adaptation to chronic illness and disability: A preliminary study of its factorial structure. Journal of Clinical Psychology in Medical Settings. 2006; 13(3):250-60. doi: 10.1007/s10880-006-9028-5

[11] Kobau R, Seligman ME, Peterson C, Diener E, Zack MM Chapman D, et al. Mental health promotion in public health: perspectives and strategies from positive psychology. American Journal of Public Health. 2011; 101(8):e1-e9. doi: 10.2105/ ajph.2010.300083

[12] Stewart ME, Watson R, Clark A, Ebmeier KP, Deary IJ. A hierarchy of happiness? Mokken scaling analysis of the oxford happiness inventory. Personality and Individual Differences. 2010; 48(7):845-8. doi: 10.1016/j.paid.2010.02.011

[13] Seligman ME, Rashid T, Parks AC. Positive psychotherapy. American Psychologist. 2006; 61(8):774-88. doi: 10.1037/0003066x.61.8.774

[14] Khodayarifard. M. [Application of positive thinking in psychotherapy with an emphasis on Islamic perspective (Persian)]. Psychology \& Education. 2000; 5(1):140-64

[15] Sheikhmoonesi F, Zarghami M, Khademloo M, Alimohammadi MM. [Happiness and associated demographic factors among medical students of Mazandaran University of Medical Sciences, 2010 (Persian)]. Journal of Mazandaran University of Medical Sciences. 2013; 22 (97) :132-137

[16] Schneider Corey M, Corey G, Corey C. Groups: Process and practice. New York: brooks/cole; 2013.

[17] Argyle M, Martin M, Crossland J. Happiness as a function of personality and social encounters. In Forgas JP, Innes J, editors. Recent advantage in social psychology: An international perspective. Amsterdam: Elsevier; 1989.

[18] Bayani AA. Test-retest reliability, internal consistency, and construct validity of the Farsi version of the Oxford Happiness Inventory. Psychological Reports. 2008; 103(1):139-44. doi: $10.2466 /$ pr0.103.1.139-144

[19] Alipour A, Agah-heris M. [Reliability and validity of the Oxford Happiness Inventory among Iranians (Persian)]. Journal of Iranian Psychologists. 2007; 3(12):287-98.

[20] Asgharipoor N, Farid AA, Arshadi H, Sahebi A. A comparative study on the effectiveness of positive psychotherapy and group cognitive-behavioral therapy for the patients suffering from major depressive disorder. Iranian Journal of
Psychiatry and Behavioral Sciences. 2012; 6(2):33-41. PMCID: PMC3940016

[21] Senf K, Liau AK. The effects of positive interventions on happiness and depressive symptoms, with an examination of personality as a moderator. Journal of Happiness Studies. 2012; 14(2):591-612. doi: 10.1007/s10902-012-9344-4

[22] Ruini C, Belaise C, Brombin C, Caffo E, Fava GA. Well-being therapy in school settings: A pilot study. Psychotherapy and Psychosomatics. 2006; 75(6):331-6. doi: 10.1159/000095438

[23] Wing JF, Schutte NS, Byrne B. The effect of positive writing on emotional intelligence and life satisfaction. Journal of Clinical Psychology. 2006; 62(10):1291-302. doi: 10.1002/jclp.20292 